\title{
QUANTIFICATION OF ENERGY EXPENDITURE DURING Gait in ChILdRen With CeREBRAL PALSY
}

\author{
Piccinini, L.; Cimolin, V.; TurCONi, A.C.; ZACCHI, S.; \\ Crivellini, M. \& Galli, M.
}

\begin{abstract}
Subjects with musculoskeletal disabilities, as children with Cerebral Palsy (CP), are characterised by some gait deviations that require greater energy expense than normal gait. While it is generally acknowledged that these patients walk inefficiently, energy expenditure is not routinely measured in most laboratories placed in clinical realities. In addition, in literature no large experience exists in term of quantification of energy expenditure on pathological subjects. From a clinical viewpoint, measurement of oxygen consumption while walking may be the best mean to quantify gait efficiency in patients and a method to determine the energetic penalty of gait disability and a patient's functional performance ability. As the goal of the treatment in CP children is, in fact, to improve function or easy the effort of the task, energy assessment is important clinically and it can give crucial information, in order to integrate other evaluations and measurements of functional limitations that are generally performed in these patients. This chapter describes the experience of the Movement Analysis Laboratory at the IRCCS "Eugenio Medea", "La Nostra Famiglia" Association, in Bosisio Parini (LC), Italy, focusing on its experience in the evaluation of energy expenditure during gait in children with $C P$.
\end{abstract}

Key words: Energy expenditure, quantitative analysis of movement, Gait, Cerebral Palsy, Rehabilitation
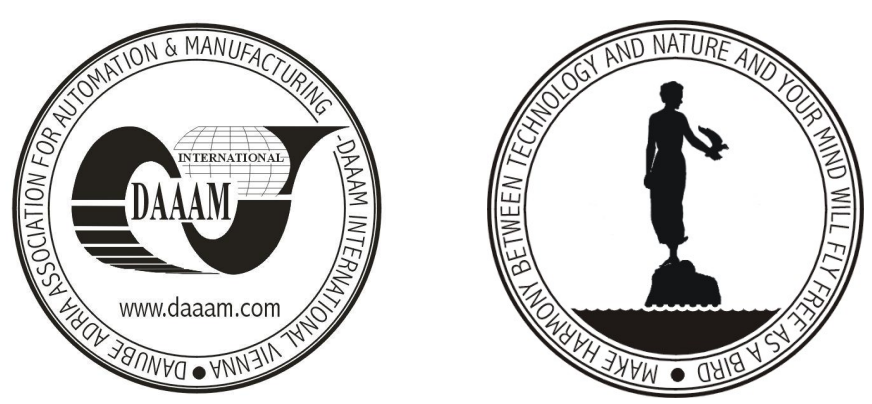

Authors' data: Dr. Piccinini, L[uigi]**; PhD. Cimolin, V[eronica]*; Dr. Turconi, A[nna] C[arla]**; Eng. Zacchi, S[ara]**; Prof. Crivellini, M[arcello]*; Prof. Galli, M[anuela]*, * Politecnico di Milano, via Golgi 39, 20133 Milano, Italy, ** IRCCS “Eugenio Medea"-"La Nostra Famiglia" Association, Bosisio Parini, via Don Luigi Monza 20, Bosisio Parini, Italy, luigi.piccinini@bp.Inf.it, veronica.cimolin@polimi.it, turconi@bp.lnf.it, sara.zacchi@bp.lnf.it, marcello.crivellini@polimi.it, manuela.galli@polimi.it

This Publication has to be referred as: Piccinini, L.; Cimolin, V.; Turconi, A.C.; Zacchi, S.; Crivellini, M. \& Galli, M. (2007). Quantification of Energy Expenditure During Gait in Children With Cerebral Palsy, Chapter 52 in DAAAM International Scientific Book 2007, B. Katalinic (Ed.), Published by DAAAM International, ISBN 3-901509-60-7, ISSN 1726-9687, Vienna, Austria

DOI: $10.2507 /$ daaam.scibook.2007.52 